\title{
The best teacher is the one who does not 'teach'!
}

\author{
P Ravi Shankar \\ Editor, JMCJMS
}

During the year 2008, I was completing my fellowship in health professions education from the PSGFAIMER Regional Institute in Coimbatore, India and had joined KIST Medical College, a new medical college at Lalitpur in the Kathmandu valley. Dr Pradhan, an engineer by profession and an educator involved with many technical education institutions in Nepal was the then chairman of KIST Medical College. As he was keenly interested in education he often, used to attend faculty meetings and educational workshops along with faculty members.

His favorite question to faculty members was 'Who is a good/best teacher?' We used to come up with traditional answers about a committed teacher who is devoted to and willing to support his/her students in whatever way possible. Dr Pradhan did not agree with our answers and used to state 'The best teacher is the one who does not teach!' Many of us asked him to explain his rather unconventional remark and he explained that one of the most important roles of a teacher is to inspire students and motivate them to seek, discover and assimilate knowledge.

As a medical educator cognizant of the recent developments in medical education I am aware of the increasing importance of developing self-directed learning skills among students and how the knowledge explosion in medicine requires healthcare practitioners to develop the skills required for lifelong learning. Developing the skills to access and assess information, and critically appraise the same is vital. Many accrediting agencies are increasingly interested in knowing how the curriculum and the teaching-learning activities in the medical school they accredit promote self-directed learning (SDL) skills among students.

Lectures continue to be the dominant method of teaching-learning in medical schools in Nepal. The focus during traditional lectures has been on factual information and many teachers of the 'old school' focus on delivering knowledge to students. The basic sciences continue to have a 'troubled' existence in the medical curriculum. The problem could be students have to learn a large amount of material without understanding its clinical relevance and application. Recent innovations in medical education have tried to address this issue through early clinical exposure, integrated learning of the basic sciences, case-based and problem-based learning. PK Rangachari, a medical educator from Canada had written about the role of the basic sciences in the medical curriculum [1]. He mentions how each subject regards itself as 
the most important in the medical curriculum and turns on the spigot drowning students in the deluge of information and forcing them to question the relevance or irrelevance of the information presented.

Student attitude towards the basic sciences was studied in a medical college in western Nepal [2]. Differences in scores were noted among male and female respondents and between the second and fourth semester students. Students were of the opinion that greater emphasis should be placed on the psychological aspects of medical treatment and on the application of the basic sciences to clinical medicine. Some of the problems in medical education may be partly because medical school teachers are not usually required to undergone training in education. For long it has been assumed that a postgraduate degree in medicine equips an individual with the skills required to teach medical students and be a faculty in medical colleges. Many colleges and universities in Nepal these days do conduct modules on education for faculty members but the emphasis varies among medical colleges.

Despite strong and increasing evidence that 'active' learning strategies are effective, many faculty members continue to have 'negative' or skeptical attitudes towards these learning methods and hold the opinion that students cannot learn unless they are taught! My personal experience as an educator in medicine has been students rarely justify their teacher's 'low' opinion about them. Large class sizes are another challenge. Active learning strategies require that students be provided with a certain amount of freedom and a minority of students may misuse this freedom to create disciplinary problems. Also I have often seen that in many disciplines and departments, practical sessions are neglected and often, 'junior' faculty members are deputed to conduct/facilitate practical sessions. Unfortunately this also extends to the clinical sciences where it has been reported that residents and postgraduates conduct majority of the bedside sessions in many institutions and senior faculty are involved only with delivering lectures. As medicine is a practical science it is unfortunate that practical sessions receive less attention compared to didactic lectures.

I strongly insist that sessions start and end on time. Preparing a lesson plan before each interactive lecture and small group session is important. I am of the opinion that teachers should go into each session with a clear idea about what they plan to do and achieve during the session. A study conducted in an Iranian medical school found that although faculty members favored lesson planning, workload and lack of knowledge were mentioned as obstacles and professors did not favor informing students about the contents of the lesson plan [3]. Research studies show that the average attention span of a student is not more than 20 minutes [4] and many educators suggest a change of activity after about 15 to 20 minutes of a session. The authors recommend that instructors be aware of individual differences in attention span. After about 40 to 50 minutes of a session a break is recommended.

I attended an Association for Medical Education in Europe (AMEE) webinar by a faculty member at the Karolinska Institute in Sweden where he discussed how they paid particular attention to architecture and interior design while designing the new medical college buildings to promote greater interaction among students, provide 'spaces' for group work and informal interactions and promote learning. With regard to lecture halls 
most colleges now emphasize halls with less length and more width. The faculty member is usually at the same or slightly higher level as the students and student seating is arranged in a horseshoe with easy mobility to enable students to form and disassemble study groups as required. Unfortunately this important area is still in its infancy in the region. AMEE has recently published a guide for aligning physical learning spaces with the curriculum [5]. The authors recommend greater involvement of academic stakeholders in the design of physical learning environments.

Technology can support student learning and is becoming more widespread and cheaper. There is a wealth of learning resources available on the internet but access to the internet is still limited in many medical colleges in Nepal. Computers and portable devices are getting cheaper and colleges can offer a variety of learning resources online. Many medical schools in developed nations record faculty sessions and post it on their learning system so that students can access the same on demand. Medical textbooks, journals, multimedia resources are also available online. Audience response technology (ART) using 'clickers' and other devices can support student involvement in sessions especially in large classrooms and promote greater interaction. A recently published Best Evidence in Medical Education (BEME) systematic review of ART on the learning outcomes in health professions education concluded that there is some evidence to suggest the effectiveness of the technology to improve learning outcomes [6]. Twitter, messaging sites and social media have also been used to create interest among students and promote interaction.
I personally take a rather dim view of faculty members exceeding the time allotted to their session. In addition to creating a number of logistic challenges for the faculty member teaching/facilitating the subsequent session this may also indicate improper planning on the part of the faculty member. Proper planning is very important; small group sessions may sometimes go beyond the time allotted as the time requirement depends on the time required for the groups to complete their tasks and present their findings. Providing material for further reading and links to research articles should stimulate student learning. A few questions could be asked from these topics during assessment to motivate students to learn them.

An article published in 2000 examines the twelve roles of a medical teacher [7]. These roles are: 'student assessor, curriculum evaluator, curriculum planner, course organizer, study guide producer, resource material creator, clinical or practical teacher, lecturer, teaching role model, on-the-job role model, learning facilitator and mentor'. At the beginning of their course of study students should have sessions devoted to accessing and assessing information, and how to be a more efficient and effective learner. Developing self-directed learning skills, and preparing students for the challenges of lifelong learning is a major challenge for medical educators worldwide. It is time that we as faculty members and educators in medicine picked up the gauntlet!

\section{REFERENCES}

1. Rangachari, P.K. Basic sciences in an integrated medical curriculum: the case of pharmacology. Adv Health Sci Edu 1997; 2: 163-171.

2. Shankar PR, Dubey AK, Subish P, Upadhyay DK. Medical student attitudes towards and 
perception of the basic sciences in a medical college in western Nepal. J Int Association Med Sci Educators 2007;17 (1):67-73.

3. Saberian M, Aghajani S, Ghorbani R, Malek M. Medical faculty members' attitude on lesson planning Semnan University of Medical Sciences. Journal of Medical Education 2003; 2 (2):61-65. Available from http://journals.sbmu.ac.ir/jme/article/viewFi le/879/782

4. Wilson K, Korn JH. Attention during lectures: beyond ten minutes. Teaching of Psychology 2007; 34(2):85-89. Available from: http://www.ministryoftruth.me.uk/wpcontent/uploads/2014/09/WilsonKorn2007Attention.pdf

5. Nordquist J, Sundberg K, Laing A. Aligning physical learning spaces with the curriculum: AMEE guide no. 107. Medical Teacher 2016; 38: 755-768.

6. Nelson C, Hartling L, Campbell S, Oswald AE. The effects of audience response systems on learning outcomes in health professions education. A BEME systematic review: BEME guide no. 21. Medical Teacher 2012; 34:e386e405.

7. Harden RM, Crosby J. AMEE guide no. 20: the good teacher is more than a lecturer-the twelve roles of the teacher. Medical Teacher $2000 ; 22: 334-347$.

\section{Correspondence to:}

Prof. P Ravi Shankar

Xavier University School of Medicine

\#23, Santa Helenastraat, Oranjestad

Aruba, Kingdom of the Netherlands.

E-mail: ravi.dr.shankar@gmail.com 